\title{
SURFACE TREATMENT EFFECT ON BULK MAGNETOELASTIC PROPERTIES OF HIGH DAMPING Fe-BASED ALLOYS
}

\author{
I.B. Chudakov and V.A. Udovenko \\ Institute of Physical Metallurgy, Moscow 107005, Russia
}

\begin{abstract}
Binary and complex alloyed high damping steels on the base of $\mathrm{Fe}-\mathrm{Cr}$ and $\mathrm{Fe}-\mathrm{Al}$ systems was investigated. It was shown that already slight surface treatment leads to the increase in magnetic anisotropy of the material and to the decrease in damping capacity.
\end{abstract}

PACS numbers: $62.40 .+\mathrm{i}, 75.50 . \mathrm{Bb}, 75.60 . \mathrm{Ej}, 75.80 .+\mathrm{q}$

\section{Introduction}

The regularities of magnetoelastic behavior contain important information concerning the interrelation between magnetic structure and fine crystalline structure of ferromagnets, especially for single-phase materials. It takes place, because the external stresses loading initiates first of all the movement of the $90^{\circ}$-magnetic domain boundaries for three-axis ferromagnets with non-zero magnetic anisotropy $[1,2]$. In the same time $90^{\circ}$-magnetic domain walls interact with all crystalline structure defects, giving rise to the appearance of long-range fields of the elastic stresses (in contrast with the $180^{\circ}$-domain walls, interacting predominantly with the defects inside the domain wall) $[3,4]$.

Magnetoelastic behavior gives rise to the very pronounced special properties of some ferromagnetic alloys - for example $\alpha$-Fe-based high damping alloys (HDAs) with the magnetomechanical damping mechanism may possess very high values of the maximum logarithmic decrement $\left(\delta_{\mathrm{m}} \approx 40 \%\right)$. The damping capacity level in these alloys is caused predominantly by the irreversible displacements of the $90^{\circ}$-type magnetic domain boundaries. Intrinsic damping is the property of a bulk material and is very sensitive (for mentioned alloys) to the slight structure modifications in the bulk of material. However, the effect of surface conditions on the magnetoelastic properties of high damping Fe-based alloys remains practically unstudied. 


\section{Experimental}

High damping alloys on the base of $\mathrm{Fe}-\mathrm{Cr}$ and $\mathrm{Fe}-\mathrm{Al}$ systems have been investigated in this paper. The alloys on the base of $\mathrm{Fe}-\mathrm{Cr}$ system contain $16-18 \mathrm{wt} . \% \mathrm{Cr}$, and $\mathrm{Fe}-\mathrm{Al}$ alloys contain from 3 to $9 \mathrm{wt} . \% \mathrm{Al}$. The concentration of impurities and nonmetallic inclusions did not exceed the following values: $0.009-\mathrm{C}, 0.13-\mathrm{Si}, 0.05-\mathrm{Mn}, 0.01-\mathrm{Ti}(\mathrm{wt} . \%)$.

The surface of alloys was subjected to the surface deformation, etching and grinding as well as to the material surface hardening (plasma nitriding), high energy laser treatment etc. The investigation of structure and properties was carried out using such methods as electron and optical microscopy, X-ray scattering, classical measurements of magnetic properties (magnetic hysteresis loops, ac susceptibility and magnetostriction) and mechanical testing. Damping capacity measurements were carried out with the help of inverted bending pendulum in the relative elongation range $\varepsilon=\Delta l / l=(0.04-1.5) \times 10^{-3}$ at frequency $\approx 40 \mathrm{~Hz}$.

\section{Results and discussion}

Damping properties tests show that after slow cooling during heat treatment both $\mathrm{Fe}-\mathrm{Cr}$ and $\mathrm{Fe}-\mathrm{Al}$ high damping alloys possess the $\delta(\varepsilon)$ dependence in the shape of curve with a sharp maximum in the field of small amplitudes [6, 7] (Fig. 2, initial state). Such a behavior is inherent in the alloys with magnetomechanical damping mechanism and is caused by the saturation of the magnetomechanical hysteresis loop upon $\varepsilon$ increase. In the same time fast samples cooling (water quenching from $T=1000^{\circ} \mathrm{C}$ ) leads to the effective suppression of damping capacity of the investigated alloys $\left(\delta_{\mathrm{m}}<4-5 \%\right)$. The reasons of such a behavior were discussed in the previous authors' papers [5-8]. It takes place, first of all, because of essential modifications in magnetic domain structure of materials.

The investigation of the effect of the surface conditions on the damping capacity of HDAs was started from the formation of special structure in the surface area with a very small macroscale elastic stresses, described by the residual deformation of the surface layer. This deformation was formed in situ in the setup for the damping capacity testing, and has an origin in the non-uniform material deformation in the bending pendulum - the surface layers are subjected to higher $\varepsilon$ values and to higher deformations. Residual deformation $\varepsilon_{\mathrm{r}}$ was calculated from the residual deflection of the sample after loading.

It was found that very small residual deformations (comparable with the saturation magnetostriction) may cause essential increase in the damping capacity of the material. The effect of initial measuring amplitude raising on the $\delta(\varepsilon)$ dependencies for the $\mathrm{Fe}-15.5 \% \mathrm{Cr}$ alloy after air-cooling from $T=1000^{\circ} \mathrm{C}$ is presented in Fig. 1. This effect is caused by such rearrangements of magnetic domain structure, which are favorable for the damping capacity of alloy. However, further increase in the $\varepsilon_{\mathrm{r}}$ value leads to the decrease in $\delta$ because of the appearance of the macro-scale residual stresses (above $\varepsilon_{\mathrm{r}} \approx \lambda_{\mathrm{s}}$ ). Such type of behavior may be illustrated by Fig. 2, where initial $\delta$ level is very high.

Higher level of the surface internal stresses was formed by means of the machine grinding of the samples. The results of the investigation of $\delta(\varepsilon)$ depen- 


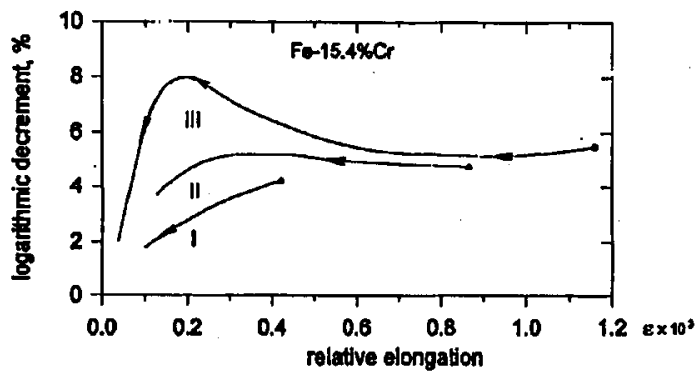

Fig. 1. The effect of the increase in vibration starting amplitude on the $\delta$ amplitude dependence of HDA $\left(\varepsilon_{\mathrm{I}}^{0}<\varepsilon_{\mathrm{II}}^{0}<\varepsilon_{\mathrm{III}}^{0}\right)$.

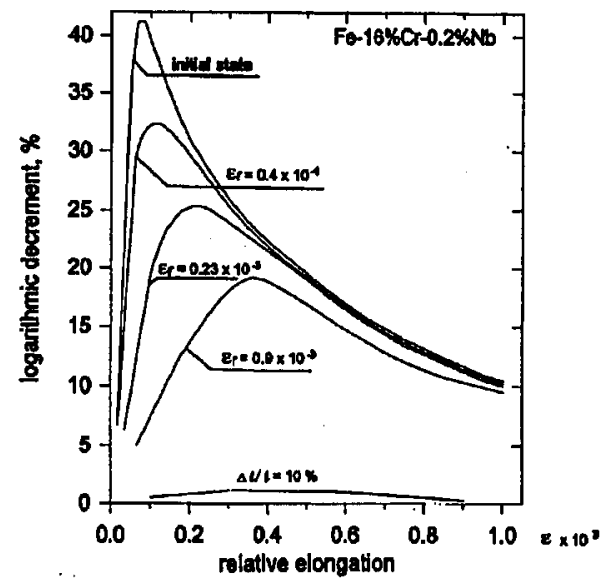

Fig. 2. The effect of small deformations of the surface layer on the damping capacity (alloy: Fe-16Cr-0.2Nb). Heat treatment: annealing $1000^{\circ} \mathrm{C} \times 40 \mathrm{~min}+$ controlled cooling (from $1000^{\circ} \mathrm{C}$ to $600^{\circ} \mathrm{C}$ with the average cooling rate $200^{\circ} \mathrm{C} / \mathrm{h}$, from $600^{\circ} \mathrm{C}$ to $400^{\circ} \mathrm{C}$ — with the average rate $400^{\circ} \mathrm{C} / \mathrm{h}$, below $400^{\circ} \mathrm{C}$ - air cooling).

dencies after surface grinding and further removing of the damaged layers using chemical etching are presented in Table. It is well known that after conventional grinding internal stresses display non-uniform distribution and possess a maximum on the depth till $20 \mu \mathrm{m}$ [10]. Upon further increase in the depth the internal stresses level tends asymptotically to the level of internal stresses of the structure, and the maximum depth of the damaged layers is considered to be not more than $\approx 200-300 \mu \mathrm{m}[10]$. As it can be seen from Table, grinding causes essential decrease in $\delta$. However, $\mathrm{Fe}-\mathrm{Cr}$ alloys are less sensitive to this treatment because of their lower thermal expansion coefficient. Removing of the damaged layers by means of etching leads to some increase in the damping capacity, however the initial level of $\delta$ was not attained even after removing of a thick layer (more than $200 \mu \mathrm{m}$ ) (Table). But initial level of $\delta$ can be recovered by additional heat treatment with 
TABLE

The effect of machine grinding and following etching on the damping capacity of the sample.

\begin{tabular}{l|l|c|c|c|c|c}
\hline \hline \multirow{2}{*}{ Alloy } & \multicolumn{3}{|c|}{ Fe-16Cr-0.7Mo-0.7Al- } & \multicolumn{3}{c}{ Fe-5.5Al [wt.\%] } \\
& $0.2 \mathrm{Nb}-0.2 \mathrm{Ti}[\mathrm{wt} . \%]$ & \multicolumn{3}{c}{} \\
\cline { 2 - 7 } & $t[\mathrm{~mm}]$ & $\delta_{\mathrm{m}}[\%]$ & $\delta_{1}[\%]$ & $t[\mathrm{~mm}]$ & $\delta_{\mathrm{m}}[\%]$ & $\delta_{1}[\%]$ \\
\hline 1000 $\mathrm{C}$, 40 min., & & & & & & \\
$\quad$ air cooling & 2.45 & 27 & 10.5 & 2.5 & 27 & 12.5 \\
grinding & 2.165 & 6 & 4 & 2.34 & 3 & 3 \\
1st etching & 2.15 & 5 & 4 & 2.31 & 3 & 2.5 \\
2nd etching & 2.10 & 7.5 & 5 & 2.27 & 3.2 & 2.5 \\
3rd etching & 2.07 & 8 & 5 & 2.24 & 3.5 & 2.5 \\
4th etching & 2.04 & 9 & 6 & 2.18 & 6.5 & 4 \\
\end{tabular}

$T>T_{\mathrm{C}}$ (the Curie point). It can be mentioned also that the damping capacity level at sufficiently high amplitudes $\left(\delta_{1}\right.$ at the amplitude $\left.\varepsilon=0.5 \times 10^{-3}\right)$ was also suppressed and its recovering process follows to $\delta_{\mathrm{m}}$ recovering (Table). This is the indication that the damping capacity was suppressed uniformly enough in all the sample volume, but not only in the surface layer. It must be mentioned that surface treatment does not influence so effectively the magnetic characteristics of alloys. Such a behavior can be explained taking into account special features of $90^{\circ}$ - and $180^{\circ}$-domain walls.

There is a principal difference between the modification of the magnetic structure of a soft magnetic material under external magnetic field and the structure modification of HDA under the field of external elastic stress. Magnetic field initiates predominantly the movement of $180^{\circ}$-domain walls, because it does not lead to essential increase in the internal elastic stresses in the structure, caused by the spontaneous lattice distortions of magnetostrictive nature. In contrast, elastic stresses cause the displacements of $90^{\circ}$-domain walls in order to minimize the energy of a system of magnetic domains. Additional differences come from the different mobility of $90^{\circ}$ - and $180^{\circ}$-domain walls, caused by the above mentioned differences in the interaction with structure defects - the mobility of $180^{\circ}$-domain walls may be more than 10 times higher than the mobility of the $90^{\circ}$-boundaries [9].

Therefore, surface elastic stresses initiate magnetic structure rearrangement because of magnetoelastic coupling not only near far to the surface, but in the bulk of material also. After the removal of the stresses origin, the domain structure modification remains unchanged because of irreversible character of the Barkhausen jumps. Induced one-axis magnetic anisotropy decreases the damping capacity, because it reduces the volume fraction of the $90^{\circ}$-magnetic boundaries, sensitive to the stresses fields. Therefore, the response of the system on external stresses loading decreases. At the same time magnetic properties will be damaged only with the decrease in the mobility of domain walls, which takes place with stronger structure modifications. In such a way magnetoelastic properties are more sensitive to the 
surface conditions than magnetic properties of three-axis ferromagnets with the moderate anisotropy.

This conclusion can be confirmed by the results of high-energy laser beam treatment of the surface of investigated alloys (performed with partial metal fusion). The experiments show that mentioned surface treatment gives rise to almost complete suppression of the high level of damping capacity $\left(\delta_{\mathrm{m}}<3-4 \%\right)$ because of formation of the very strong anisotropy of material. This anisotropy cannot be removed even using a high temperature annealing $\left(1200^{\circ} \mathrm{C}, 1.5 \mathrm{~h}\right)$ because it was formed at very high temperatures during fast crystallization process.

The behavior of investigated alloys after surface hardening (plasma nitriding) is quite similar to the described above. Indeed, the elastic stresses appear because of lattice enrichment by implanted atoms as well as nitrides precipitation. The surface achieves very high hardness ( $H V$ till $2000 \mathrm{MPa}$ and higher), and the depth of the hardened layers may be propagated to $\approx 0.15 \mathrm{~mm}$. At the same time the damping capacity decreases with the increase in the hardened layer width. However, additional annealing makes available the partial recovery of the damping capacity. These peculiarities seem to be of the practical importance and may be used during the development of alloys, possessing the combination of sufficiently high damping capacity and the desired values of the surface hardness. Treatment procedure and following annealing regimes must be developed directly for the real application.

\section{Conclusions}

1. Already a slight surface treatment leads to the appearance of pronounced magnetic anisotropy of high damping alloys on the base of $\mathrm{Fe}-\mathrm{Cr}$ and $\mathrm{Fe}-\mathrm{Al}$ systems. Induced anisotropy causes the decrease in damping capacity because of the reduction of the volume fraction of $90^{\circ}$-magnetic domain boundaries.

2. Damping characteristics of the high damping alloys with magnetomechanical damping mechanism are more sensitive to the surface conditions than the magnetic properties of the soft magnetic materials because of the principal differences between $180^{\circ}$ - and $90^{\circ}$-boundaries of magnetic domains.

3. The surface of high damping $\mathrm{Fe}-\mathrm{Cr}$ and $\mathrm{Fe}-\mathrm{Al}$ alloys may be hardened in order to improve special exploitation properties of material.

\section{References}

[1] A. Cochardt, in: Magnetic Properties of Metals and Alloys, American Soc. Metals, Cleveland (Ohio) 1959, p. 328.

[2] I.B. Kekalo, Phys. Met. Heat Treat. 7,5 (1973).

[3] S. Chikasumi, Physics of Ferromagnetism. Magnetic Characteristics and Engineering Applications, Syokabo, Tokyo 1984, p. 287.

[4] J. Degauque, in: Proc. Int. Symp. on Mech. Spectroscopy, AGH, Kraków 1991, p. 125.

[5] V.A. Udovenko, S.I. Tishaev, I.B. Chudakov, Physics-Doklady 38, 168 (1993).

[6] V.A. Udovenko, S.I. Tishaev, I.B. Chudakov, Russ. Metall. 1, 64 (1994).

[7] V.A. Udovenko, I.B. Chudakov, N.A. Polyakova, Phys. Met. Metall. 75, 247 (1993). 
[8] V.A. Udovenko, Nukleonika 39, 149 (1994).

[9] H. Trauble, A. Seeger, Z. Angew. Phys. 21, 299 (1966).

[10] I.A. Birger, Residual Stresses, Mashinostroenije Publ., Moskva 1963, p. 264. 